EPJ Web of Conferences 59, 08011 (2013)

DOI: $10.1051 /$ epjconf/20135908011

(C) Owned by the authors, published by EDP Sciences, 2013

\title{
Analysis of damaging effects of laser-plasma accelerated shrapnels on protecting glass shield
}

\author{
Michaela Martinkova ${ }^{1, a}$, Milan Kalal ${ }^{1}$ and Mikhail L. Shmatov ${ }^{2}$ \\ ${ }^{1}$ Czech Technical University in Prague, FNSPE, Prague, Czech Republic \\ 2 Ioffe Physical Technical Institute, St. Petersburg, Russia
}

\begin{abstract}
Analysis of the damage caused by laser plasma accelerated fragments of metal target was performed. Measured as well as calculated parameters of craters and shrapnel found in BK7 glass blastshield are presented. Method applied for the measurement of parameters of craters is described. Potential damage of optical elements by the so-called striking cores (high-velocity stable objects arising due to collapse of cones or some other target parts toward their axes) that can be generated in IFE related experiments is evaluated.
\end{abstract}

\section{INTRODUCTION}

Operation of the Inertial Fusion Energy (IFE) power plants and the experiments related to IFE can be accompanied by the formation of the high-velocity, high-density objects that can damage optical elements and/or other equipment unless some measures to prevent this are not taken [1-5]. In many situations the effect of such objects on the equipment will be similar to that of the micrometeorites and space debris on the equipment operating in space. Below, we provide data from analysis of craters and target fragments (shrapnel) found in the BK7 protecting glass shield after interaction of $\sim 600 \mathrm{~J}$ laser pulse with the target with a cavity. We use the formulae from [6-10] to estimate the velocities of those shrapnel and to analyze possible damage of transparent optical elements of IFE power plants and experimental facilities by the so-called striking cores.

\section{EXPERIMENTAL DATA AND THEIR ANALYSIS}

Shrapnel generated in experiments employing high-energy lasers (generally with masses in the range from several micrograms to few tens or even hundreds milligrams) can reach energies sufficient to severely damage or to destroy a glass plate made of fused silica, BK7, or similar kinds of glasses with the thickness up to several millimeters. This may result in a serious damage or even destruction of the diagnostics and optical components located in the path of such objects when these components are not shielded or otherwise protected [1-5].

Below, an analysis of damaging effects of the laser-plasma accelerated $\mathrm{Cu}$ fragments on $8 \mathrm{~mm}$ thick, $315 \mathrm{~mm}$ in diameter, blastshield made of BK7 glass is presented. Blastshield originated from the Prague Asterix Laser System (PALS). Dominant part of the damage was caused during a single shot experiment using the so-called Reverse Pressure Acceleration (RPA) target schema (targets with a cavity) [11-13]. Target, located a distance $50 \mathrm{~cm}$ away from the blastshield, was irradiated by the first

\footnotetext{
ae-mail: martimi2@fjfi.cvut.cz
}

This is an Open Access article distributed under the terms of the Creative Commons Attribution License 2.0, which permits unrestricted use, distribution, and reproduction in any medium, provided the original work is properly cited. 
harmonics $(1315 \mathrm{~nm})$ of PALS iodine laser with a pulse duration $\sim 350 \mathrm{ps,} \mathrm{energy} \sim 600 \mathrm{~J}$, and intensity $\sim 6 \times 10^{14} \mathrm{~W} / \mathrm{cm}^{2}$, cavity facing laser.

For estimation of the volume (and mass) of the material removed from selected craters their replicas were prepared. This was done by plasticine pressed into the craters using a very thin protective plastic foil (not affecting the craters' replicas shape). The foil constitutes not more than $3 \%$ of the total volume of each crater. This way, replicas of a reasonably good accuracy and reproducibility were obtained. Minimal dimensions of the structure recordable by this method with required precision and reproducibility were estimated to be of the order of $0.1 \mathrm{~mm}$ in diameter. For the scope of this work objects of diameter higher then $1 \mathrm{~mm}$ were analyzed. Plasticity of the plasticine allows for a careful removal of the reliefs (corresponding solely to the crater) from the plasticine subbase and a subsequent formation of this subtracted material into a sphere. Diameters of those spheres were estimated with precision of about $0.05 \mathrm{~mm}$ using the photography of such sphere positioned on the ruler. This procedure represents relatively fast and accurate method for estimation of the parameters of relief structures.

Some of examined craters were of very irregular shape. The biggest crater maximum diameter was $\sim 1.4 \mathrm{~cm}$, while its depth was $\sim 0.2 \mathrm{~cm}$. The shape of the craters was close to cones with the angle at the base (the blastshield surface) varied from about 4 to 22 degs. The aspect ratio of measured craters, i.e. the ratio of the crater's diameter to its depth, varied from $\sim 27$ (smaller craters) to $\sim 5$ (larger craters), the corresponding interpolation gave dependance $D_{c r} / P_{c r}=130 \cdot D_{c r}[\mathrm{~mm}]^{-1.6259}$ for aspect ratio and $D_{c r}[\mathrm{~mm}]=3 \cdot V_{c r}\left[\mathrm{~mm}^{3}\right]^{0.2821}$ for crater diameter. From examination of the blastshield it was found that several smaller craters contained remains of shrapnel sealed in the glass. The measured as well as calculated parameters of those shrapnel and the corresponding craters are shown in table 1 . It was found that their masses varied from circa $0.03 \mathrm{mg}$ to $0.8 \mathrm{mg}$, assuming the density presented in table 1 . It shall be noted that the abrasive nature of glass can reduce volume (mass) of metallic fragments during their interaction with glass. When estimating the shrapnel velocities, the diameter of the crater $D_{c r}$ created in the glass with density $\rho_{\text {glass }}$ in the situation when the vector of the projectile velocity is perpendicular to the glass surface was described using the equations

$$
D_{c r}=5 \times 10^{-4} \rho_{\text {glass }}^{-0.5} \rho_{p}^{0.71} d_{p}^{1.13} v_{p}^{0.754}
$$

$[6,7,10]$ and

$$
D_{c r}=5 \times 10^{-4} \rho_{\text {glass }}^{-0.5} \rho_{p}^{0.784} d_{p}^{1.076} v_{p}^{0.727}
$$

[7], all substituted in cgs units.

For the borosilicate glass CMX, the ratio of the predicted to the actual values of $D_{c r}$ is in the range of about 0.2 to 3 [7]. Eqs. (1) and (2) are the different approximations of the experimental data [6, 7, 10]. The value of $d_{p}$ was chosen as a parameter providing the equality of the volume of the ball with such a diameter and that of the remains of shrapnel estimated using microscope.

Mechanical properties of BK7 glass were studied also using a $5.5 \mathrm{~mm}$ (22”) caliber air gun in order to evaluate possible effect of collision of non-irradiated target with glass. For this purpose a $10 \mathrm{~mm}$ thick, $315 \mathrm{~mm}$ in diameter, BK7 shield was used. The velocity of projectile, measured at the distance corresponding to the actual distance of the tested blastshield, was about $122 \mathrm{~m} / \mathrm{s}$. The mass of the lead projectile $m_{p}$ used for the experiment (22" Diabole Boxer), was $0.858 \pm 0.004 \mathrm{~g}$, its kinetic energy was $6.4 \mathrm{~J}$. No crater was created. The impact of the projectile caused three significant cracks going from the impact epicenter to the edge of the plate to the points where the blastshield was fixed. In the impact epicenter, the uncomplete circle of very weakly damaged glass surface, corresponding to the diameter of the projectile transformed after impact, became noticeable. Only antireflection coatings was possibly affected. During the impact the projectile was shrank to the length of about $1.7 \mathrm{~mm}$ from the original $8 \mathrm{~mm}$. 
IFSA 2011

Table 1. Parameters of $\mathrm{Cu}$ fragments found in smaller craters and parameters of smaller and larger craters.

\begin{tabular}{llllllllll}
\hline \multicolumn{1}{l}{ SMALLER CRATERS } & \multicolumn{10}{c}{ LARGER CRATERS } \\
\hline \multicolumn{2}{l}{$\rho_{B K 7}=2.53 \mathrm{~g} / \mathrm{cm}^{3}$} & \multicolumn{1}{l}{$\rho_{C u}=8.96 \mathrm{~g} / \mathrm{cm}^{3}$} & \multicolumn{2}{l}{$\rho_{B K 7}=2.53 \mathrm{~g} / \mathrm{cm}^{3}$} \\
$D_{c r}[\mathrm{~mm}]$ & $V_{c r}\left[\mathrm{~mm}^{3}\right]$ & $m_{p}[\mathrm{mg}]$ & $d_{p}[\mathrm{~mm}]$ & $v_{p}[\mathrm{~m} / \mathrm{s}]$ & $D_{c r}[\mathrm{~mm}]$ & $P_{c r}[\mathrm{~mm}]$ & $D_{c r} / P_{c r}$ & $V_{c r}\left[\mathrm{~mm}^{3}\right]$ \\
\hline $2.0 \pm 0.3$ & $0.48 \pm 0.06$ & 0.717 & 0.535 & 534 & 515 & $8.4 \pm 0.6$ & $1.8 \pm 0.3$ & 4.67 & 37.4 \\
$2.3 \pm 0.3$ & $0.70 \pm 0.11$ & 0.0269 & 0.179 & 3320 & 3150 & $5.3 \pm 0.9$ & $1.03 \pm 0.06$ & 5.15 & 7.70 \\
$1.47 \pm 0.21$ & $0.52 \pm 0.08$ & 0.269 & 0.386 & 5790 & 5460 & $7.6 \pm 1.1$ & $0.97 \pm 0.06$ & 7.84 & 21.1 \\
$1.8 \pm 0.4$ & $0.13 \pm 0.06$ & 0.0986 & 0.276 & 1250 & 1190 & $7.5 \pm 1.5$ & 1 & 7.5 & 13.4 \\
$0.98 \pm 0.06$ & $0.14 \pm 0.10$ & 0.538 & 0.486 & 239 & 222 & $3.8 \pm 0.6$ & $0.22 \pm 0.03$ & 17.3 & 1.77 \\
$1.10 \pm 0.06$ & - & 0.358 & 0.424 & 342 & 319 & $6.7 \pm 0.1$ & 1 & 6.7 & 18.8 \\
$1.8 \pm 0.2$ & - & 0.269 & 0.386 & 757 & 722 & $3.5 \pm 0.9$ & $0.23 \pm 0.04$ & 15.2 & 9.20 \\
1.5 & - & 0.179 & 0.337 & 729 & 687 & $2.75 \pm 0.96$ & 0.1 & 27.5 & 0.45 \\
1.1 & - & 0.806 & 0.556 & 228 & 214 & & & & \\
1 & - & 0.645 & 0.416 & 310 & 288 & & & & \\
\hline
\end{tabular}

\section{THEORETICAL PREDICTIONS OF POSSIBLE DAMAGING EFFECTS OF STRIKING CORES}

The failure of ignition of the fast ignition targets with the cones and the non-ignition experiments with such target can result in the formation of striking cores [3]. They arise due to collapse of the metal cones, hemispheres and parts having some other shapes toward their axes with velocities that are not sufficient for formation of cumulative jets (see Refs. [3,15-17]). The limitation on the velocity of collapse seems to restrict the maximum velocity of the striking cores, that can arise in the IFE experiments, by the value of about 3 to $5 \mathrm{~km} / \mathrm{s}$. In contrast with the cumulative jets, striking cores are not influenced by the hydrodynamic instabilities and, as a result, do not decay [3,15-17]. The large mass and the high stability of striking cores result in their high danger for the equipment [3].

When estimating the possible damage of the optical elements by the striking core, let us consider the situation when the striking core is formed from the whole material of the golden cone with the inner base radius $r=0.9 \mathrm{~mm}$, the height $h=1.4 \mathrm{~mm}$, and the wall thickness $l=30 \mu \mathrm{m}$. Volume $V_{\text {cone }}$ of the material of this cone is about $1.4 \times 10^{-4} \mathrm{~cm}^{3}$. The choice of $r$ and $h$ is based partly on the example presented in Ref. [19] for the fast ignition, indirect compression, NIF-scale target. The thickness of the cone wall of this target equals to $30 \mu \mathrm{m}$ in the region near the tip and is about $190 \mu \mathrm{m}$ in the region near the base [19]. Thus, the assumption used here corresponds to the relatively small value of $V_{\text {cone }}$. The shape of the striking core will be determined by several factors (see also Refs. [15, 17]). Let us assume that the damage of the optical element by the striking core is approximately the same as that caused by the spherical projectile with the same volume, density, and velocity.

According to Ref. [9], the depth $P_{c r}[\mathrm{~cm}]$ and the diameter $D_{c r}[\mathrm{~cm}]$ of the crater created by the spherical projectile with the diameter $d_{p}[\mathrm{~cm}]$, density $\rho_{p}\left[\mathrm{~g} / \mathrm{cm}^{3}\right]$ and velocity $v_{p}[\mathrm{~km} / \mathrm{s}]$ in the fused silica in the situation when the vector of the projectile velocity is perpendicular to the surface of the glass are given by

$$
P_{c r}=0.226 \rho_{p}^{0.595} d_{p}^{1.05} v_{p}^{0.995}
$$

and

$$
D_{c r}=9.656 \rho_{p}^{0.373} d_{p}^{1.183} v_{p}^{0.915} .
$$

Here it is assumed that the thickness of the fused silica is sufficiently large, namely, at least about 2 to 3 times greater than $P_{c r}$, and, therefore, the penetration of the projectile through it does not occur (see Ref. [8]).

In the experiments with the two-stage light gas gun launcher the ratio of the predicted value of $P_{c r}$, corresponding to Eq. (3), to the actual one was in the range from about 0.4 to about 1.6, the ratio of 
the predicted value of $D_{c r}$, corresponding to Eq. (4), to the actual one was in the range from about 0.4 to about 1.9. Other approximations describing $P_{c r}$ and $D_{c r}$ also exist, their relative accuracies are approximately the same as those of Eqs. (3) and (4) (see, e.g., Ref. [8, 9]).

The aforementioned value of $V_{\text {cone }}$ corresponds to $d_{p} \approx 6.4 \times 10^{-2} \mathrm{~cm}$. Substituting this value, the density of gold $\rho_{A u}=19.32 \mathrm{~g} / \mathrm{cm}^{3}$ [20], and $v=3 \mathrm{~km} / \mathrm{s}$ into Eqs. (3) and (4), we obtain $P_{c r} \approx 0.22 \mathrm{~cm}$, $D_{c r} \approx 3.1 \mathrm{~cm}$.

Substituting into Eqs. (1) and (2) the density of the borosilicate glass BK7 $\rho_{g}=2.53 \mathrm{~g} / \mathrm{cm}^{3}[20]$ and the parameters of the aforementioned golden projectile, we obtain $D_{c r} \approx 1.56 \mathrm{~cm}$ and $D_{c r} \approx 1.60 \mathrm{~cm}$, respectively (the results are presented with three significant digits in order to demonstrate that in the situation under consideration the values are practically identical).

Substituting the aforementioned parameters of striking core and the density of fused silica $\rho_{\text {glass }}=$ $2.201 \mathrm{~g} / \mathrm{cm}^{3}$ [20] into Eqs. (1) and (2), we obtain $D_{c r} \approx 1.67 \mathrm{~cm}$ and $D_{c r} \approx 1.71 \mathrm{~cm}$, i.e. values which are slightly higher then those for BK7 but still very close each other, however, about twice lower then those from equation (4). Note that the difference between the predictions of Eqs. (1), (2) and that of Eq. (4) corresponds to the aforementioned accuracy of these equations.

The kinetic energy of the striking core under consideration would be $\varepsilon_{K} \approx 12 \mathrm{~J}$.

\section{CONCLUSION}

The measured as well as calculated parameters of craters and shrapnel found in BK7 glass blastshield after the experiment conducted at PALS in 2009 were presented. Based on the examination of these parameters some correlations in between them were estimated. The calculated velocities of fragments varied from about $220 \mathrm{~m} / \mathrm{s}$ to $5800 \mathrm{~m} / \mathrm{s}$. The corresponding energies varied from about 0.01 to $5 \mathrm{~J}$. For measuring the parameters of craters, such as their volume, the original method was employed. In the experiment with airgun it was found that for creation of visible craters in BK7 the velocity of $\sim 120 \mathrm{~m} / \mathrm{s}$ is not sufficient for $\sim 800 \mathrm{mg}$ projectile. Estimations of presumed parameters of the striking cores, arising from the interaction of laser with especially formed targets, presented in Sect. 3 for fused silica and BK7, reveled that the striking cores can cause strong damage to optical elements. Therefore, for the IFE power plants the use of the active protection of vulnerable optical elements from the striking cores and other high-density, high-velocity objects, such as the elimination of such objects in flight by the laser or electron beams, seems to be highly desirable or even necessary, because otherwise the rate of the change of the damaged protective transparent elements can be too high (see also Refs. [1-5, 8]).

The authors would like to thank to J. Skala, E. Krousky, J. Ullschmied, V. Kmetik, T. Piszarczyk, J. Badziak, S. Borodziuk, and T. Chodukowski for their help related to provision of the blastshield and relevant information as well as useful discussions, and the anonymous Referees for the useful comments on the first version of this paper. This research has been partly supported by the MEYS of the Czech Republic Research Project LC528 and by CZ.1.05/1.1.00/02.0061.

\section{References}

[1] M. Tobin, et.al., Fusion Eng. Des. 60, 85 (2002)

[2] M.L. Shmatov, Fusion Eng. Des. 60, 65 (2002)

[3] M.L. Shmatov, Fusion Sci. Technol. 43, 456 (2003)

[4] W.R. Meier and W.J. Hogan, Fusion Sci. Technol. 49, 532 (2006); 52, 118 (2007) (corrigenda)

[5] D.C. Eder, et.al., J. Phys.: Conf. Ser. 112, 032023 (2008)

[6] H. Fechtig, et.al., NASA SP-370 (1974)

[7] K.G. Paul, et.al., Int. J. Impact Eng. 20, 627 (1997) 


\section{IFSA 2011}

[8] B.G. Cour-Palais, Int. J. Impact Eng. 23, 137 (1999)

[9] R.R. Burt and E.L. Christiansen, Int. J. Impact Engineering 29, 153 (2003)

[10] R. Verker, et.al., Acta Materialia 52, 5539 (2004)

[11] J. Badziak, et.al., ArXiv:1001.0679

[12] J. Badziak, et.al., Appl. Phys. Lett. 96, 251502 (2010)

[13] S. Borodziuk, et.al., Appl. Phys. Lett. 95, 231501 (2009)

[14] J. Yang, et.al., EPJ Web of Conferences 6, 39001 (2010)

[15] R.W. Wood, Proc. Roy. Soc. Ser. A 157, 249 (1936)

[16] V.M. Titov, Doklady AN SSSR 247, 1082 (1979) [Sov. Phys. Doklady (1979)]

[17] E.I. Zababakhin and I.E. Zababakhin, Yavleniya Neogranichennoi Kumulyatsii [Phenomena of Unlimited Cumulation] (Nauka, Moscow 1988).

[18] S.P. Hatchett, et.al., Fusion Sci. Technol. 49, 327 (2006)

[19] S.S. Berdonosov, Fizicheskaya Encyclopedia [Physical Encyclopedia] (Editor-in-Chief A. M. Prokhorov, V. 2, Sovetskaya Encyclopedia, Moscow 1990) 87

[20] http://www.glassdynamicsllc.com/ 